\title{
DE AMORES E MENTORES: (DES)APRENDIZAGENS DO FEMININO EM NARRATIVAS DE CLARICE LISPECTOR
}

\author{
Eliane Fittipaldi Pereira ${ }^{1}$
}

\begin{abstract}
Resumo
Este ensaio estuda a figura do mentor em duas narrativas de Clarice Lispector: "Obsessão" e Uma Aprendizagem ou o Livro dos Prazeres, em que a paixão das heroínas Cristina e Loreley por seus mentores, Daniel e Ulisses, determinam profundas transformações em seu modo de ser e de agir. Essas narrativas se conjugam para (des)construir um conceito de feminino que transita entre o patriarcalismo repressor e a autonomia desejada.
\end{abstract}

\section{Palavras-chave}

Aprendizagem. Lispector. Feminino. Amor. Mentores.

Ele era um homem, ela era uma mulher, $e$ milagre mais extraordinário do que esse só se comparava à estrela cadente que atravessa quase imaginariamente o céu negro e deixa como rastro o vívido espanto de um Universo vivo. Era um homem e era uma mulher.

Uma Aprendizagem ou o Livro dos Prazeres, 1998, p. 27.

Em várias narrativas de Clarice Lispector, chama a atenção a presença de uma figura masculina um tanto recorrente: trata-se de um "sujeito suposto saber", um professor e/ou mentor, que exerce grande fascínio na protagonista e que a conduz, pelo bem ou pelo mal, a diferentes tipos de aprendizagem e desaprendizagem a respeito da vida, do que é ser mulher e, sobretudo, de que mulher ela é.

Não raro ela se apaixona por ele. Não raro se decepciona, ao perceber que o saber nele suposto é insuficiente, ou inadequado, ou inexistente.

\footnotetext{
${ }^{1}$ Pela Universidade de São Paulo, é Mestre em Língua e Literatura Francesa e Doutora em Literatura Portuguesa, com Pós-Graduação em Tradução e Pós-Doutorado em Literatura Brasileira. Lecionou Língua Francesa Avançado, Literatura Norte-Americana e Teoria da Literatura na PUC-SP, Comunicação Empresarial na FGV e Literatura Portuguesa na USP. Hoje, dedica-se a traduções literárias, cursos e palestras ad hoc nas áreas de Literatura Comparada, Tradução Literária e Tradução Intersemiótica.
} 
Isso ocorre, por exemplo, no primeiro romance de Clarice, Perto do Coração Selvagem (1943). Também ocorre no conto “O Crime do Professor de Matemática”, que consta dos livros A Legião Estrangeira (1964) e Felicidade Clandestina (1971).

Com foco nesse tema, destaco aqui o conto "Obsessão", um dos primeiros por ela escritos, em 1941 (quando tinha apenas 21 anos), e publicado pela primeira vez, postumamente, no volume A Bela e a Fera, em 1979. Destaco também o romance Uma Aprendizagem ou o Livro dos Prazeres, publicado em 1969, quando ela já era uma mulher entre os 47 e os 49 anos, com a experiência de um casamento e um divórcio, do lançamento de cinco romances, e publicação de vários contos que conquistaram a admiração da crítica e do público.

Minha intenção é contrastar, nessas duas narrativas, a relação que os mentores Daniel de "Obsessão" e Ulisses de Uma Aprendizagem ou o Livro dos Prazeres estabelecem com as protagonistas Cristina e Loreley, respectivamente, e verificar como eles as levam, por diferentes caminhos, a uma autoconscientização. Embora as personalidades de ambos sejam contrastantes e suas "pedagogias" praticamente antípodas, é sob a orientação deles que essas duas mulheres desaprendem um modo de ser e de se comportar que não lhes convém e aprendem a respeito de quem são e daquilo que são capazes.

Se "Obsessão" configura uma relação tóxica em que o poder se sobrepõe ao amor, despertando a protagonista para a consciência de sua própria força mas lançando-a na solidão existencial, Uma Aprendizagem baseia-se no enfrentamento dessa solidão e da preparação para o amor com vistas a uma conjunção mais autêntica e igualitária.

Assim é que, paralelas nas semelhanças e dessemelhanças, as duas narrativas formam um panorama de relações em que o amor, a desaprendizagem de "códigos sociais opressivos" (LADEIRA, 2019, p. 93) e a aprendizagem de um modo de ser mais legítimo conjugam-se para construir e desconstruir um feminino que ainda transita entre um patriarcalismo repressor e uma autonomia desejada.

Começo por "Obsessão", em que Cristina se instaura como narradora para contar, a posteriori, "seu caso" conturbado com Daniel, procurando nem "perdoar" nem "acusar" - expressões essas que, como ocorre com o próprio título do conto, indiciam, em prolepse, a história de um erro e de um transtorno.

Essa narradora suspeitíssima, que admite confundir "fatos e pensamentos" mas afirma ser "tudo verdade", começa por fornecer informações fundamentais para o estabelecimento de causalidades ao descrever quem era e como vivia antes de conhecer 
Daniel. Fala de sua infância serena, passada em um ambiente pequeno-burguês onde "o hábito há muito alargara caminhos certos", descreve sua entrada na adolescência dócil, um tanto apática e inteiramente passiva, determinada de fora ("Até que um dia em mim descobriram uma mocinha, abaixaram meu vestido, fizeram-me usar novas peças de roupa e consideraram-me quase pronta" (LISPECTOR, 1999, p. 31) e menciona seu casamento, aos 19 anos, com Jaime, pessoa de "temperamento pouco ardente" casamento esse que já durava seis anos quando o que aconteceu "aconteceu simplesmente".

Nesse relato, algumas circunstâncias chamam a atenção: o modo distraído como ela é formatada, pelos pais, em boa filha; o desejo impreciso de "casar, ter filhos e, finalmente, ser feliz"; a vida conjugal insossa com um homem que perpetua o modelo familiar; o papel assumido de esposa acomodada, cujo estado de alienação apática é denominado por ela como uma "feliz cegueira", que no entanto encobre uma "vaga insatisfação". Ela assim o descreve:

Às vezes, melancolia sem causa escurecia-me o rosto, uma saudade morna e incompreensível de épocas nunca vividas me habitava. Nada romântica, afastava-as logo como a um sentimento inútil que não se liga às coisas realmente importantes. Quais? Não as definia bem e englobava-as na expressão ambígua "coisas da vida". Jaime. Eu. Casa. Mamãe.

\section{$[\ldots]$}

Se aquela vaga insatisfação vinha me inquietar, eu, sem saber explicála e habituada a conferir um nome claro a todas as coisas, não a admitia ou atribuía-a a indisposições físicas. Além disso, a reunião de domingo em casa de meus pais, junto às primas e vizinhos, qualquer bom e animado jogo reconquistavam-me rapidamente e repunham-me na estrada larga, de novo a caminhar entre a multidão de olhos fechados." (LISPECTOR, 1999, p. 33)

Esse trecho do conto, escrito em 1941, configura uma situação feminina já descrita por Simone de Beauvoir em 1939 n’O Segundo Sexo. Uma situação que se agrava com o decorrer dos anos e acaba sendo novamente denunciada na década de 60 por Betty Friedan, que a caracteriza como o "problema inominado" [the unnamed problem] da mulher cuja vida pré-determinada ao desempenho do papel de esposa-mãe-dona de casa pelos discursos de autoridade (família, igreja, escola, medicina, mídia) revela-se angustiante.

Diz Friedan em seu livro Mística Feminina, publicado em 1963: 
O problema permaneceu mergulhado, intacto, durante vários anos, na mente da mulher americana [e enfatizo aqui: não só da americana, mas da mulher ocidental de classe média burguesa - assim também da francesa, assim também da brasileiral. Era uma insatisfação, uma estranha agitação, um anseio de que ela começou a padecer em meados do século XX, nos Estados Unidos. Cada dona de casa lutava sozinha com ele, enquanto arrumava camas, fazia as compras, escolhia tecido para forrar o sofá, comia com os filhos sanduíches de creme de amendoim, levava os garotos para as reuniões de lobinhos e fadinhas e deitava-se ao lado do marido, à noite, temendo fazer a si mesma a silenciosa pergunta: 'E' só isto?'”. (FRIEDAN, 1971, p. 17, comentário meu entre chaves, em itálico)

Cristina não se faz essa pergunta. Mas é assim que essa personagem, produzida 22 anos antes da publicação de Mística Feminina, mesmo sem exercer a função de mãe, já é tomada pelo "problema inominado". Ela entra em depressão, apanha uma febre tifoide e, para recuperar-se, é levada, por exigência da família, a Belo Horizonte - como narra em primeira pessoa no conto, "subitamente lançada numa liberdade que eu não pedira e da qual não sabia me utilizar”. Na pensão em que se hospeda vive Daniel, cujo discurso transgressor constitui "uma melodia encantada, qual canto de sereia, que ameaça arrancar Cristina de sua cômoda ignorância”. (ROSENBAUM, 2006, p. 100)

Sem ser percebida, Cristina ouve as conversas de Daniel, em que máximas e aforismos tais como "não há fundamento para o dever" ou "as realizações matam o desejo" a fazem vislumbrar um modo de viver em que é possível "não aceitar, escolher, revoltar-se", libertar-se de injunções e entrar em contato com o próprio desejo. Mas, como comentadora crítica da própria história, ela revela, ainda em prolepse, que "Daniel era o perigo. E para ele eu caminhava".

Irremediavelmente atraída por esse poder discursivo, Cristina inicia, com Daniel, uma relação que descreve como cada vez mais opressiva, na qual se vê como inferior e entende a atenção dele como um favor; uma relação desigual em que é tratada com indiferença, superioridade, arrogância e desprezo. Ele chega mesmo a falar-lhe de maneira insultuosa, expressa no texto, tanto em discurso indireto:

Minha boca estupidamente aberta, 'meus olhos tolos, atestando minha ingenuidade de animal'... Era assim que Daniel falava comigo. (LISPECTOR, 1999, p. 38)

[...] porque ele não hesitava em falar sobre a minha falta de inteligência, com as expressões mais cruéis. (LISPECTOR, 1999, p. 42) 
Como também em discurso direto:

- Cristina, você sabe que vive?

- Cristina, é bom ser inconsciente?

— Cristina, você nada quer, não é mesmo? (ibid.)

Nesse mesmo tom sarcástico e desonroso, Daniel faz a proposta de "educá-la" que é dramatizada no discurso direto: “- Cristina, você quer que eu a acorde?”. (ibid, p. 43)

A partir daí, Daniel torna-se seu mentor ou, melhor, seu "guia mefistofélico" no dizer de Rosenbaum (2006, p. 105). A posição que ele assume no processo de aprendizagem da protagonista é a dominante, de quem sabe mais. O método que utiliza é ao mesmo tempo peripatético (baseado em "passeios estranhos e reveladores"), dissertativo ("ele falava, eu ouvia") e impositivo, funcionando como uma lavagem cerebral ("deixe que minha voz seja o seu pensamento").

Os objetivos de Daniel são inocular, em Cristina, a dor ("o segredo da vida é sofrer") e promover o embotamento de suas sensações e sentimentos: “-É preciso saber sentir, mas também saber como deixar de sentir." (LISPECTOR, 1999, p. 48) Mergulhado em abstrações que, aliadas ao desprezo da corporeidade e à racionalidade exacerbada, matam a alegria simples de viver, ele promove uma aprendizagem por contaminação e envenenamento.

Daniel constitui uma força narcísica centrípeta que arrasta, para seu vórtice de infelicidade, essa jovem que nunca desenvolveu a capacidade de questionamento e o senso crítico - mas que é curiosa, que busca, que percebe haver algo mais além da imanência em que vive.

Duas questões, porém, chamam a atenção nas entrelinhas desse processo.

Primeira: quem é que seduz quem? É Daniel quem seduz Cristina com sua postura de transgressor que sabe das coisas e domina o discurso, ou é ela quem o seduz com sua ingenuidade, fragilidade, simplicidade e adaptação ao mundo? Muito sutilmente, o texto dá a entender que é ela quem o aborda e dá início à relação.

Outra questão a considerar é a adesão dela a esse tratamento humilhante e sua identificação com a perversidade dele — indicando que tal característica também é dela e que nessa humilhação há um gozo. Afinal, o comportamento sádico só ocorre com a anuência do masoquista, e o masoquista é, a seu modo, também sádico. 
De qualquer modo, é assim que a obsessão se instala e que Cristina se vê presa a esse processo de aprendizagem e desaprendizagem que passa pela dor — dela e de sua família - e pelo reconhecimento da agressora que ela mesma é.

Sendo chamada de volta a casa porque a mãe está doente, ela procura se readaptar, mas não consegue. Passa a experimentar um conflito crescente entre a retomada da vida insípida com o marido e a possibilidade de uma vida nefasta com Daniel até que, como este previa, decide voltar a Belo Horizonte, tornar-se sua amante e retomar sua educação sentimental. Mas não sem antes escrever, ao marido, uma carta impregnada da crueldade com que aprendeu a ser tratada. Ela já reproduz o comportamento aprendido, já exerce o sadismo que aprendeu com Daniel.

É assim que, em sua nova vida, basta-lhe estar "junto do poderoso, do que sabia", criando o hábito de cuidar dele "minuto a minuto". Nessa nova situação, ela "nunca sorria, desaprendera da alegria" e constantemente temia ser por ele abandonada.

Até que um episódio doméstico faz a situação inverter-se. Ela subitamente descobre que é necessária a Daniel, desencanta-se com a ideia que fazia dele, de — nas palavras dela - "um deus", um "ídolo", e passa a apresentar-lhe resistência: "Tornei-me cruel. Ele tornou-se fraco [...]." (ibid, p. 58)

Ambos passam a empreender uma luta de atos e palavras na qual o orgulho predomina e a tensão se torna insuportável: “Armamo-nos e éramos duas forças”.

E essas forças se enfrentam finalmente quando um dia de chuva em que se encontram confinados lhes propicia um diálogo repleto de tensão e em que Daniel deixa clara a posição que Cristina ocupa nessa relação já desgastada: à pergunta dela, “— [...] Não somos dois?”, ele responde: “—-Não. Estás só. Sempre estiveste só”. (ibid, p. 80).

É então que ela, ainda atordoada por essa revelação, assume gradualmente o poder sobre a própria palavra a ponto de torná-la performativa pela repetição. Cristina diz cinco vezes que vai embora enquanto ambos fazem movimentos indicativos de antagonismo, até serem capazes de render-se ao "nosso mistério que deveria ser o mesmo". E, após convencer a si mesma do que está dizendo, ela toma a decisão final de, de fato, abandonálo e retornar à vida anterior, não mais a mesma: a mãe morrera de um ataque do coração causado por sua partida, o pai "refugiara-se" no interior e o marido procura banalizar o ocorrido denominando-o "deslize", porém nunca mais se aproxima dela.

O que Cristina desaprende com Daniel? A alegria, a ingenuidade, o comodismo e, de algum modo, a submissão e a conformidade às regras. 
O que aprende? A identificar sua própria inclinação para a maldade sob o estereótipo de "boa moça", recusar uma situação de poder que humilha e fragiliza, analisar os próprios sentimentos e sensações, pagar o preço de suas escolhas. E aprende, mais que tudo, a apropriar-se do discurso que a institui como sujeito, que lhe propicia organizar-se como indivíduo e lhe fornece o entendimento possível de sua experiência e seu destino.

Cristina aprende a distinguir-se do rebanho manso que vive em estado de permanente alienação de si: singulariza-se. Aprende a solidão. E aprende a tornar-se sujeito de sua própria história — sujeito de si em lugar de sujeita ao outro e, na medida do possível, ao grande Outro, que agora, não mais alienada, questiona e critica.

Também Loreley ou Lóri, a protagonista de Uma Aprendizagem ou o Livro dos Prazeres, inicia sua trajetória de aprendizagens e desaprendizagens a partir de um enamoramento. Como no caso de Cristina e Daniel, é seduzida por Ulisses, que um dia encontra por acaso, e ao mesmo tempo o seduz. Porém aqui é ele, o navegador experiente, quem corre o risco de naufragar ao relacionar-se com ela. E isso por duas razões: porque ela vem cumprindo um destino indicado em seu nome altamente motivado, alusivo à sereia do Reno que atrai os barqueiros para os rochedos; e porque nada tem a compartilhar com ele, além de sua angústia e um corpo anestesiado pela repressão das sensações, pelo medo de sentir a dor que de qualquer modo sente.

Assim é que, diferentemente de Cristina, Lóri inicia sua trajetória a partir da dor de existir (da angústia) e faz de tudo para amortecê-la: "a vida inteira tomara cuidado em não ser grande dentro de si para não ter dor" (LISPECTOR, 1998, p. 56). Ela parece até ter aprendido ao pé da letra os ensinamentos do Daniel de "Obsessão" para anular sua força de potência e embotar-se, já que "[...]havia cortado [a dor] sem sequer ter outra coisa que em si substituísse a visão das coisas através da dor de existir, como antes”. (LISPECTOR, 1998, p. 56)

Acontece que quem assume o comando dessa relação é Ulisses. E Ulisses, na tradição homérica, é o mais astuto dos homens. Ele sabe que quem não vive a dor tampouco vive a alegria e se recusa a uma união amorosa com Lóri até ela entrar em contato com suas sensações e sentimentos em um périplo de autoconhecimento que se propõe a orientar. Como o herói da Odisseia, ele sabe que tem de se amarrar fortemente 
ao mastro de seu propósito: o de unir-se a Lóri somente quando ela constituir um "corpoalma"; sabe que tem de tapar os ouvidos (e às vezes os olhos) para não sucumbir à sedução fatal que o fará naufragar, já que Lóri buscará atraí-lo com seu “desejo de ser possuída por Ulisses sem ligar-se a ele, como fizera com os outros" (LISPECTOR, 1998, p. 42). E sabe que terá de abrir espaço para que ela mesma trace seu caminho.

Embora Ulisses seja professor de Filosofia, sua postura em relação a Lóri nada tem de professoral. Ele a incentiva a aprender por si e compartilha com ela, nessa jornada a que ambos se propõem, o papel da Penélope que, com paciência, tece laços para a união consciente. Assim como determina que Lóri espere por ele, já que não a quer alienada de si, obriga-se a esperar pela (des)aprendizagem dela, que acabará ocorrendo durante o ciclo de um ano (começando no verão e terminando na primavera), período em que Lóri aprenderá que, para viver, é necessário morrer e nascer constantemente. Seu percurso não é retilíneo, com começo, meio e fim: configura-se como uma espécie de espiral, caracterizada por avanços e retrocessos, sempre ampliada e enriquecida a cada retrocesso e avanço. Sua busca, que é em si mesma uma busca inseparável da linguagem que a constitui, faz-se um processo instável, cheio de oscilações, rupturas, lapsos, alterações de velocidade. Tudo isso está na linguagem, que é por vezes fragmentada, desarticulada, paradoxal, redundante e até contraditória. Uma Aprendizagem é um livro irregular, que provocou as mais variadas reações da crítica, desde a taxação de "subliteratura para baixo" por parte de Léo Gilson (apud ARÊAS, 2005, p. 27) até a louvação como "romance de romances" por parte de Benedito Nunes (1973, p. 72).

De início, Lóri espera aprender com Ulisses por ele ser professor de Filosofia, mas logo se dá conta de que o caminho de sua aprendizagem não irá passar por teorias, restando-lhe, portanto, captar o extraordinário a partir da própria rotina simples. É assim que ela aguça a percepção sensorial nas feiras livres e mercados de peixe; é assim que briga com Deus e desconstrói a noção antropomórfica que Dele comumente se faz; é assim que tem vivências relativas a mitos ancestrais (como morder a maçã paradisíaca ou passar pelo famoso ritual do banho de mar, na metade do livro). É assim que ressignifica sentidos embotados pela cultura.

Tudo isso é acompanhado a uma distância segura por Ulisses, que apoia, comenta, vibra, apazigua, decepciona-se às vezes, irrita-se um pouco quando Lóri procura "queimar as etapas" e algumas vezes chega a ser rude com ela em sua franqueza sem modalizações - quando, por exemplo, lhe diz coisas como: “esse corpo que nem é bonito mas é o corpo que eu quero" e "você, além de esconder o que se chama alma, tem vergonha de ter um 
corpo". Ele se mantém firme orientando pouco, afastando-se para que essa aprendizagem de reconstrução da subjetividade aconteça nela (e nele) sem nada forçar. E diz a ela: “Não estou aqui porque quero lhe dar lições, se não fosse por outros motivos, porque também eu estou aprendendo com dificuldade” (LISPECTOR, 1998, p. 96).

Ulisses vem se dedicando há mais tempo do que Lóri à aprendizagem de si, mas sabe que jamais estará "pronto em todos os sentidos". Portanto, ele também aprende e desaprende no contato com ela. E sua (des)aprendizagem tampouco é fácil: ela o obriga a enfrentar o próprio desejo, a própria arrogância, a máscara do intelectual superior, o academicismo, o dogmatismo e inclusive o machismo - que chega a admitir ao dizer, por exemplo: "Mas meu lado de relíquia de ancestrais faz com que eu fique contente de ver uma mulher que não bebe" (LISPECTOR, 1998, p. 94). Clarice finalmente o põe de joelhos diante de uma Lóri que também se ajoelha e faz questão de dizer a ele: "Aprendo contigo mas você pensa que eu aprendi com tuas lições, pois não foi, aprendi o que você nem sonhava em me ensinar" (LISPECTOR, 1998, p. 157).

Para além da mistura os pronomes de tratamento, o que essas palavras definem é o verdadeiro aprendizado: aquele em que o mentor não diz "faça o que eu digo", nem tampouco "faça o que eu faço"; mas aquele em que um eu reconhece um tu como alteridade e lhe envia sinais de acolhimento e desafio para que esse eu possa vir a tornarse quem é; e também para que esse $t u$, sendo quem é, possa assim permanecer aos olhos do eu. Quem descreve de alguma maneira esse processo é o filósofo Gilles Deleuze quando afirma:

Nada aprendemos com aquele que nos diz: faça como eu. Nossos únicos mestres são aqueles que nos dizem "faça comigo" e que, em vez de nos propor gestos a serem reproduzidos, sabem emitir signos a serem desenvolvidos no heterogêneo. (DELEUZE, 1988, p. 31)

Cristina e Lóri, voluntária ou involuntariamente, aprendem mais do que os mentores lhes ensinam. Da relação insalubre de "Obsessão" à comunhão de corpos e almas em Uma Aprendizagem, muito foi elaborado pelo feminino. Se a voz que constrói e põe fim à narrativa de 1941 é a da mulher que fracassa em obter liberdade no mundo mas a obtém no uso da palavra, a voz que encerra a de 1969 é a do mentor Ulisses —aberta em dois pontos. 
Diferentemente de Cristina que, após a (des)aprendizagem, encerra seu relato com a palavra "sozinha" e um ponto final, Lóri e Ulisses terminam o romance juntos e humanamente iguais, presenteando um ao outro com a própria solidão... embora ele faça a Lóri a proposta conservadora de se casarem e terem filhos, além de já a avisar que ela "terá de ficar sozinha muitas vezes" porque seu trabalho vai aumentar e ele vai precisar escrever.

Essa voz que a reinstala na ordem patriarcal e os dois pontos que a suspendem sugerem que eles voltam ao ponto de partida para iniciar um novo caminho de aprendizagem e desaprendizagem; que, na relação amorosa incipiente, o casal, ainda que procure não cair nas antigas armadilhas do patriarcado, não irá transgredir os papéis sociais pré-determinados; que o caminho é sempre desconhecido, não importa quanto dele já se tenha percorrido; e que esse caminho jamais termina, que esses dois ainda têm muito o que aprender, agora juntos.

Os dois pontos finais parecem equivaler a um ponto de interrogação referente à seguinte pergunta: mesmo sendo Ulisses mais conhecedor de si e mais pedagogicamente eficaz que Daniel e mesmo tendo Lóri se transformado em uma mulher sem "modos nem formas", terá esse casal, que é emblemático do casal do futuro, maiores oportunidades de uma união saudável e transformadora?

A pergunta fica para o leitor. Para isso é que há finais abertos.

Consideremos, porém, o seguinte.

Se Lóri e Ulisses tratam de "consumar o seu amor confiantes, de mãos dadas, como sócios que trocam experiências diferentes mas enriquecedoras" (BARBOSA, 2001, p. 141), este talvez seja o único romance de Clarice com final feliz — um romance que ensine a amar caso seja lido como uma proposta à maneira da Bildung ${ }^{2}$ e dentro dos objetivos de prodesse et delectare (ensinar e deleitar), que são os da arte poética segundo Horácio $^{3}$.

Entretanto, tal leitura provoca certa desconfiança à luz da atitude paródica e irônica que permeia o romance e da visão de mundo negativa e desestabilizadora que se revela em todas as outras obras da escritora. Clarice mesma parece invalidá-la quando se refere da seguinte maneira a Uma Aprendizagem (livro que, apud AREASS, 2005, p. 35, ela dizia

\footnotetext{
${ }^{2}$ Conceito de formação do indivíduo marcado por um ideal de educação com base na razão, próprio do Iluminismo do século XVIII.

3 "Aut prodesse volunt aut delectare poetae aut simul et iucunda et idonea dicere vitae." [Ou ser úteis ou deleitar querem os poetas, ou, simultaneamente, cantar alegrias e utilidades à vida]. (FLACCUS, 1994, p. 11, versos 333-334)
} 
ser "detestável e malfeito"): "É uma história de amor. E duas pessoas já me disseram que aprenderam a amar através desse livro. Pois é”. (Apud GOTLIB, 2008, p. 381)

Que dizer desse "pois é?", senão que Clarice talvez tenha detectado, nos depoimentos de seus leitores, um desvio de recepção? Que dizer dele a não ser que Uma Aprendizagem, com sua ironia, seu vanguardismo, sua liberdade e sua própria busca de "não ter modos nem formas", vai na contramão da Bildung por não ter em vista a "formação racional" da personagem nem a do leitor? E que "amar" é um processo singular, para o qual não há modelo nem prescrição (exatamente o que o livro demonstra)?

Cristina e Lóri são mulheres (fictícias, mas nem por isso menos mulheres) de transição na luta por maior autonomia, mulheres que estão se deslocando de uma cultura falocêntrica para outra que inclui posturas feministas como vias de superação; são mulheres que oscilam entre a adesão à representação dos papéis de gênero e a transgressão dos preceitos do patriarcado. Importa que, a partir da experiência de si mesmas que passa mais pela exposição aos acontecimentos que pelo entendimento - pois "entender era sempre limitado" (LISPECTOR, 1998, p. 43) e "compreender era sempre um erro" (ibid, p. 44) —, elas se tornam mais consciente de suas escolhas.

Quanto aos homens que as mentoram durante esse processo de (des)aprendizagem, também eles sofrem as injunções do patriarcado, são oprimidos por identidades estereotipadas a eles impostas, sentem o peso dos papéis que os discursos de poder lhes atribuem e se veem diante do desafio de reinventar-se:

Os personagens de Lispector [...] estão sempre tensamente submetidos à tradição patriarcal em sua dinâmica de obediência a valores que, se aparentemente se mostram mais vantajosos para os homens, acabam por aprisionar e reprimir a todos, não importantdo o sexo, a classe, a etnia ou a idade. (HELENA, 1992, p. 1167)

Se Cristina e Lóri sofrem por viverem aquém de si mesmas — por estarem subordinadas a expectativas sociais que as encolhem -, Daniel e Ulisses também sofrem, pela mesma razão às avessas: por estarem submetidos aos mesmos códigos sociais patriarcais, que antinomizam fragilidade e masculinidade e deles exigem uma imagem de 
poder, força, conhecimento, sabedoria. As duas moças assumem como verdades e certezas o que eles lhes dizem, procuram aprender essas "verdades e certezas" para melhor conhecerem a si mesmas, a eles e ao mundo e, para isso, sujeitam-se às regras de relacionamento que eles lhes impõem. Daniel e Ulisses, por sua vez, mascaram sua vulnerabilidade adotando posturas pedantes e até mesmo cínicas em relação a elas, que reagem conforme suas relações vão revelando assimetrias. Lóri, de seu lado, irrita-se com a arrogância de Ulisses em determinado momento e vai a uma festa em busca de outros homens; além disso, corta os cabelos à revelia dele e passa, ela mesma, a determinar os padrões de espera e encontro na relação. Já Cristina custa a reagir à violência verbal de Daniel, volta para ele depois do intervalo que lhe propicia reflexão e somente se rebela contra o poder emocional e intelectual que ele exerce sobre ela quando percebe o calcanhar de aquiles do companheiro, assim como a força e o poder que ela mesma detém. Se em Uma Aprendizagem há um compartilhamento de aprendizagens com graus variados na distribuição de poder e um resultado em aberto (indiciando possibilidades de simetria), em "Obsessão" essa distribuição é pendular e chega a um extremo danoso para ambas as partes.

Assim, essas duas narrativas nos apresentam dois tipos de (des)aprendizagem do feminino. Uma delas é a que ocorre sob o domínio perverso do homem que (a exemplo de Daniel) se enrijece na molaridade de seus valores falocêntricos e não abre mão do poder de subjugar o feminino e extrair um gozo desse poder, ainda que dolorido. Aprendizagem na qual a mulher parece vítima e cúmplice; e na qual o homem parece vilão e vítima - quando, na verdade,

Não há vítima nem algoz nas relações entre homens e mulheres nas obras de Clarice, mas uma circunstância gerada pelos condicionamentos sociais e mantida pela falta de conhecimento sobre as possibilidades de eles vivenciarem sua autonomia. (GROB-LIMA, 2009, p.77)

O outro tipo de (des)aprendizagem é aquele feito junto ao homem que (como Ulisses) detecta em si mesmo a posição tradicional de hegemonia e busca uma mobilidade que o leve a ressignificar suas funções para um modo de viver mais autêntico e livre, que o desloque para modos de ser mais adequados a uma parceria harmônica com a mulher, admitindo sua alteridade e respeitando-a. Um homem que é capaz de avaliar em 
profundidade as consequências de uma cultura falogocêntrica, a falsidade que seus rígidos padrões acarretam, e que a julga pestífera:

Não temos sido puros e ingênuos para não rirmos de nós mesmos e para que no fim do dia possamos dizer "pelo menos não fui tolo" e assim não ficarmos perplexos antes de apagar a luz. Temos sorrido em público do que não sorriríamos quando ficássemos sozinhos. Temos chamado de fraqueza a nossa candura. Temo-nos temido um ao outro, acima de tudo. E a tudo isso consideramos a vitória nossa de cada dia. Mas eu escapei, disso, Lóri, escapei com a ferocidade com que se escapa da peste, Lóri, e esperarei até você também estar mais pronta. (LISPECTOR, 1998, pp. 48-49)

Há uma questão a mais a ressaltar aqui: produzindo os devires dessas protagonistas que aprendem e desaprendem a respeito da vida, do amor, do masculino e do feminino e de tantas outras coisas, há uma mulher que aprende e desaprende uma escrita, uma escritura. É Clarice que, entre os 21 e os 49 anos de idade, experimentou muitos "modos e formas" literários a ponto de chegar a dizer que "gênero não me pega mais" (e entendemos que essa palavra, "gênero", no contexto deste ensaio, pode significar tanto categoria literária como identidade sexual).

De "Obsessão" até Uma Aprendizagem sua própria escrita passa por diversas transformações, dentre as quais ressaltamos:

\begin{tabular}{|c|}
\hline "OBSESSÃO" \\
\hline ênfase nos acontecimentos \\
\hline maior causalidade nas ações \\
\hline mais fábula \\
\hline espécie de "argumento" \\
\hline ênfase na construção do sujeito \\
\hline final fechado (fecho de ouro)
\end{tabular}

\begin{tabular}{|c|}
\hline UMA APRENDIZAGEM \\
\hline mais perscrutação da interioridade \\
\hline maior fragmentação da trama \\
\hline mais poeticidade \\
\hline mais ironia e paródia \\
\hline ênfase na desconstrução do sujeito \\
\hline
\end{tabular}


Assim, se em "Obsessão" as normas do gênero "conto" são mais respeitadas, as do gênero "romance" (principalmente do "romance de amor" tradicional) passam por uma crítica e uma subversão em Uma Aprendizagem (o que também ocorre com as normas que determinam os gêneros masculino e feminino). Há que perceber, nesse livro, certo cinismo (às vezes sutil, às vezes pesado) desconstruindo o formato do folhetim (FRANCO JUNIOR, 2008) e propondo a reversão de sua leitura: uma crítica aguda não apenas ao modo de se ver a mulher dentro de uma sociedade conservadora, mas ao modo como se forma essa mulher e tradicionalmente se escreve para essa mulher; uma crítica, também, ao modo de se ver o amor em uma sociedade burguesa. Sua ironia, do tipo que beira o sarcasmo, leva o/a receptor/a a situar-se no lugar mesmo que é ironizado. É o tipo de ironia capaz de desconstruir, entre as dicotomias, aquelas que se costuma estabelecer entre a alta e a baixa literatura (no caso, a epopeia e o romance cor-de-rosa); a arte e a mercadoria; o certo e o errado em termos de composição romanesca; a personagem dita "esférica" e a considerada "plana"; o sublime e o ridículo; a representação e a não representação; e até mesmo o figurativo e o abstrato.

A questão é que de "Obsessão" a Uma Aprendizagem ou o Livro dos Prazeres, da narrativa convencional ancorada na causalidade à narrativa mais irônica, mais crítica e autocrítica e mais livre de categorizações, Clarice abriu caminho não apenas aos papéis que o homem e a mulher são capazes de desempenhar na sociedade, mas às potencialidades da expressão poética — aprendiz e mentora privilegiada de si mesma que foi e que nos ensina a ser em seu legado inesgotável.

\section{Referências}

AREAS, Vilma. Clarice Lispector com a Ponta dos Dedos. São Paulo: Companhia das Letras, 2005.

BARBOSA, Maria José Somerlate. Clarice Lispector: Des/fiando as Teias da Paixão, Porto Alegre: EDIPUCRS, 2001.

DELEUZE, Gilles. Diferença e Repetição. Tradução de Luiz Orlandi, Roberto Machado. Rio de Janeiro: Edições Graal, 1988.

FLACCUS, Quintus Horatius. Ars Poetica, Arte Poética. Tradução de Mauri Furlan, [18 a.C. $]$ 1994. Arquivo eletrônico. Disponível em https://document.onl/documents/horacio-arte-poetica-5620266836d09.html. Acesso em 17 de ago. 2020. 
FRANCO JR., Arnaldo. “Uma aprendizagem ou o livro dos prazeres, de Clarice Lispector, romance moderno e romance de mocinha". In: Signótica, vol. 18, n 1, pp. 116, 2008. Disponível em https://www.revistas.ufg.br/index.php/sig/article/view/3716 Acesso em 14 dez. de 2017.

FRIEDAN, Mística Feminina. Tradução de Áurea B. Weissenberg. Petrópolis: Vozes, 1971.

GOTLIB, Nádia Batella. Clarice Fotobiografia. São Paulo: Editora da Universidade de São Paulo/Imprensa Oficial do Estado de São Paulo, 2008.

GROB-LIMA, Bernardete. O percurso das personagens de Clarice Lispector. Rio de Janeiro: Garamond Universitária, 2009.

HELENA, Lucia. A Problematização da narrativa em Clarice Lispector. In: Hispania, v. 75, n. 5, dez. 1992, pp. 1164-1173.

LADEIRA, Antonio. "Figuras da mundivisão masculina em Clarice Lispector". Revista do Programa de Estudos Pós-Graduados em Literatura e Crtítica Literária da PUC-SP, $\mathrm{n}^{\mathrm{o}}$ 23, dezembro de 2019, p. 88-103. Disponível em https://revistas.pucsp.br/fronteiraz/article/view/44495. Acesso em 22 out. 2020.

LISPECTOR, Clarice. Uma Aprendizagem ou o Livro dos Prazeres. Rio de Janeiro: Rocco, 1998.

LISPECTOR, Clarice. “Obsessão”. In: A Bela e a Fera. Rio de Janeiro: Rocco, 1999, pp. 31-61.

NUNES, Benedito. Leitura de Clarice Lispector. São Paulo: Quiron, 1973.

ROSENBAUM, Yudith. Metamorfoses do Mal: uma leitura de Clarice Lispector. São Paulo: Editora da Universidade de São Paulo: Fapesp, 2006.

\title{
ON LOVERS AND MENTORS: (UN)APPRENTICESHIPS OF THE FEMININE SUBJECT IN TWO NARRATIVES BY CLARICE LISPECTOR
}

\begin{abstract}
This essay focuses on two narratives by Clarice Lispector: "Obsessão" [Obsession] and Uma Aprendizagem ou o Livro dos Prazeres [An Apprenticeship or the Book of Pleasures], in which the heroines' passion for their mentors determine deep transformations on their way of being. Both narratives conjugate to construct and deconstruct a feminine subject that is moving from a repressive patriarcal system to a much desired autonomy.
\end{abstract}

\section{Keywords}

Apprenticeship. Lispector. Feminine. Love. Mentors. 